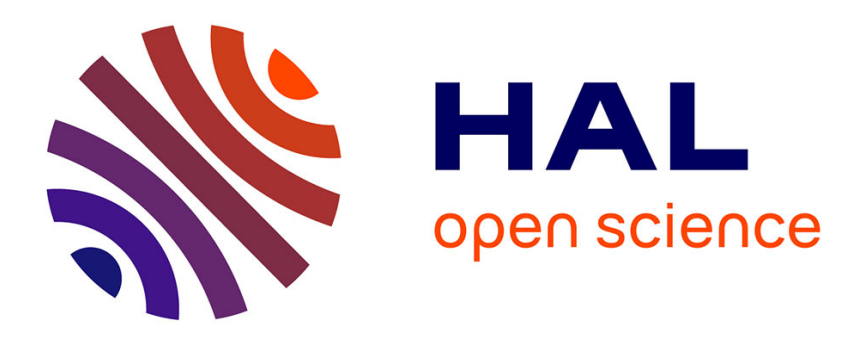

\title{
Bending settlement of a slab resting on a consolidating foundation
}

\author{
Maurice A. Biot, F. M. Clingan
}

\section{To cite this version:}

Maurice A. Biot, F. M. Clingan. Bending settlement of a slab resting on a consolidating foundation. Journal of Applied Physics, 1942, 13 (1), pp.35-40. 10.1063/1.1714800 . hal-01368646

\section{HAL Id: hal-01368646 \\ https://hal.science/hal-01368646}

Submitted on 21 Sep 2016

HAL is a multi-disciplinary open access archive for the deposit and dissemination of scientific research documents, whether they are published or not. The documents may come from teaching and research institutions in France or abroad, or from public or private research centers.
L'archive ouverte pluridisciplinaire HAL, est destinée au dépôt et à la diffusion de documents scientifiques de niveau recherche, publiés ou non, émanant des établissements d'enseignement et de recherche français ou étrangers, des laboratoires publics ou privés. 


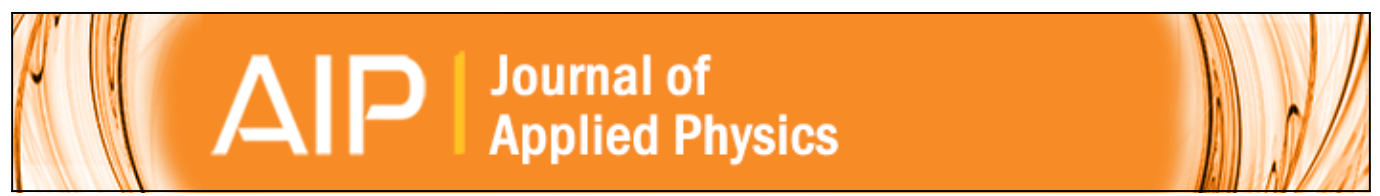

\section{Bending Settlement of a Slab Resting on a Consolidating Foundation}

M. A. Biot and F. M. Clingan

Citation: Journal of Applied Physics 13, 35 (1942); doi: 10.1063/1.1714800

View online: http://dx.doi.org/10.1063/1.1714800

View Table of Contents: http://scitation.aip.org/content/aip/journal/jap/13/1?ver=pdfcov

Published by the AIP Publishing

\section{Articles you may be interested in}

Solving the Beam Bending Problem with an Unilateral Winkler Foundation

AIP Conf. Proc. 1389, 1820 (2011); 10.1063/1.3636963

Deflection of a Particle Moving along an Infinite String Resting on an Elastic Foundation

J. Acoust. Soc. Am. 38, 282 (1965); 10.1121/1.1909657

A General Solution for the Bending of Beams on an Elastic Foundation of Arbitrary Continuity

J. Appl. Phys. 21, 55 (1950); 10.1063/1.1699420

Consolidation Settlement of a Soil with an Impervious Top Surface

J. Appl. Phys. 12, 578 (1941); 10.1063/1.1712940

Consolidation Settlement Under a Rectangular Load Distribution

J. Appl. Phys. 12, 426 (1941); 10.1063/1.1712921

\section{High Energy Nanosecond Lasers}

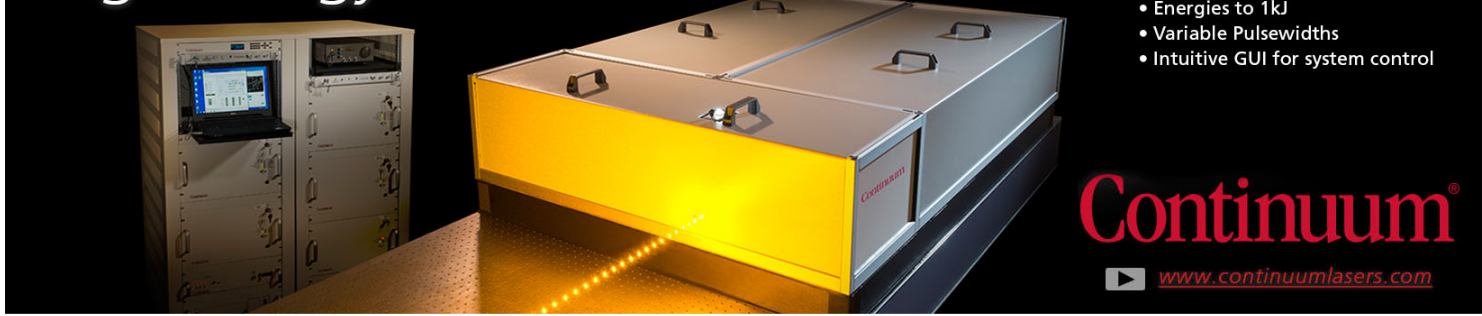




\title{
Contributed Original Research
}

\section{Bending Settlement of a Slab Resting on a Consolidating Foundation}

\author{
M. A. Biot* and F. M. Clingan \\ California Institute of Technology, Pasadena, California
}

(Received August 26, 1941)

\begin{abstract}
The calculation of the settlement and bending of an elastic slab resting on a consolidating foundation under the action of a load concentrated on a line. Two cases are considered: first, when the slab is perfectly pervious to water, and second, when it is impervious. The problem is two-dimensional.
\end{abstract}

\section{SETTLEMENT OF A PERFECTLY POROUS SLAB UNDER A SINUSOIDALLY DISTRIBUTED LOADING}

IN previous papers ${ }^{1,3}$ the problem of settlement 1 was considered in case the load was directly applied to the soil. We shall now evaluate the settlement for the case where an elastic slab is interposed between the load and the soil. The problem is analogous to that of the bending of a beam on an elastic foundation which was treated in an earlier publication. ${ }^{2}$ In fact it may be considered as a particular case of the present problem.

We shall first evaluate the settlement of a slab under a sinusoidally distributed load. Consider a slab of stiffness $E I$ per unit width resting on a foundation. The vertical deflection $w$ under a vertical load $p(x)$ and a reaction $p_{1}(x)$ of the soil satisfies the differential equation

Putting

$$
E I d^{4} w / d x^{4}=p(x)-p_{1}(x) .
$$

we find

$$
\begin{aligned}
w & =w_{0} \cos \lambda x, \\
p & =p_{0} \cos \lambda x, \\
p_{1} & =A \cos \lambda x,
\end{aligned}
$$

$$
E I \lambda^{4} w_{0}=p_{0}-A .
$$

This is a relation between the beam deflection

* On leave of absence from Columbia University.

${ }^{1} \mathrm{M}$. A. Biot, "Consolidation settlement under a rectangular load distribution," J. App. Phys. 12, 426 (May, 1941).

${ }^{2}$ M. A. Biot, "Bending of an infinite beam on an elastic foundation,"J. App. Mech. 4, (March, 1937).

'M. A. Biot and F. M. Clingan, "Consolidation settlement of a soil with an impervious top surface," J. App. Phys. 12, 578 (July, 1941). and the soil reaction. Another relation between the soil reaction and the deflection has been obtained in a previous paper. ${ }^{2}$ Assuming the Poisson ratio to be zero $(\nu=0)$ formula (1.8) of this previous paper yields in operational form

$$
w_{0}=\frac{A a}{\lambda}\left[1+\frac{1}{\left[1+p /\left(\lambda^{2} c\right)\right]^{3}}\right],
$$

where $a=1 / 2 G$ is the compressibility and $p$ is the differential operator $\partial / \partial t$ with respect to time.

From (1.2) and (1.3) we derive

$$
w_{0}=\frac{p_{0} a}{\lambda\left[E I \lambda^{3} a+\frac{1}{1+1 /\left[1+p /\left(\lambda^{2} c\right)\right]^{3}}\right]} .
$$

Now we are interested primarily in the settlement due to consolidation. We therefore subtract from $w_{0}$ the initial elastic deflection at $t=0$. This deflection is obtained by putting $p=\infty$ in the expression for $w_{0}$. The value of the settlement is therefore

$$
w_{s}=\left\{w_{0}-\frac{p_{0} a}{\lambda\left[E I \lambda^{3} a+1\right]}\right\} \cos \lambda x .
$$

The following notation is introduced

$$
E I a=b^{3} \text {, }
$$

where $b$ is a characteristic length and $\gamma=b \lambda$. Then the settlement may be written

$$
w_{s}=b a p_{0} \frac{1}{\gamma\left(\gamma^{3}+1\right)} \cdot \frac{\left(\gamma^{3}+1\right)\left[1+p /\left(\lambda^{2} c\right)\right]^{\frac{1}{2}}-\gamma^{3}}{\left[\left(\gamma^{3}+1\right)^{2}\left(1+p /\left(\lambda^{2} c\right)\right)-\gamma^{6}\right]} .
$$


Actually this expression is an operator by which it is possible to find the time settlement relation when the sinusoidal load is applied suddenly at

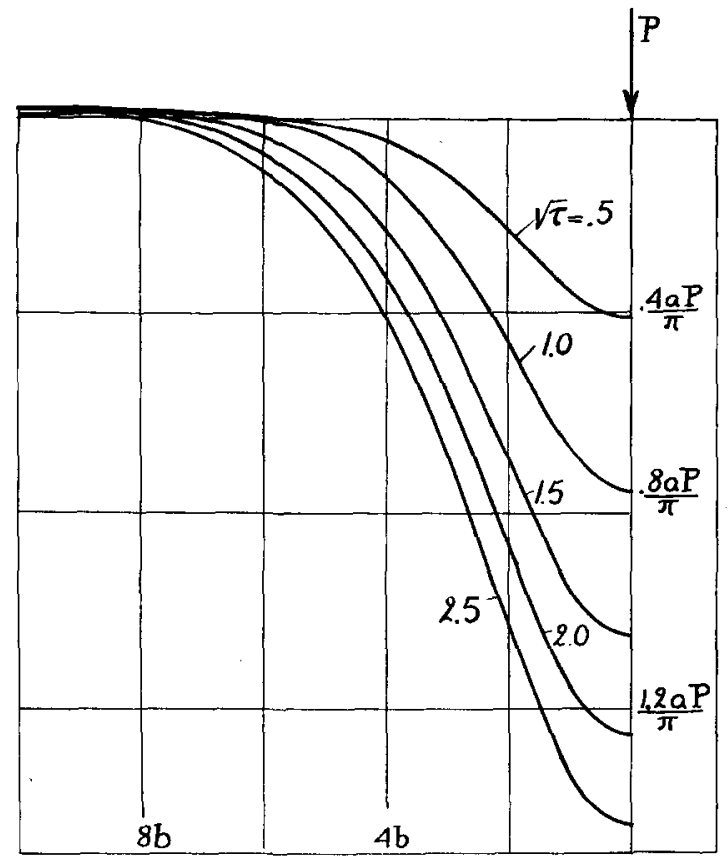

Fig. 1. Settlement of a pervious slab under a concentrated load $P$ at various instants $\left(\sqrt{ } \tau=\left(c^{t}\right)^{l / b} / b\right)$.

the instant $t=0$. The two operators appearing in the above expressions lead to the following functions

$$
\begin{aligned}
\frac{(1+p)^{\frac{1}{2}}}{p+\alpha} 1(t) & =\frac{1}{\alpha} P(\sqrt{ } t)-\frac{(1-\alpha)^{\frac{1}{2}}}{\alpha} e^{-\alpha t} P\left[((1-\alpha) t)^{\frac{1}{2}}\right], \\
\frac{1}{\beta+p}-1(t)= & \frac{1}{\beta}\left(1-e^{-\beta t}\right),
\end{aligned}
$$

where

Putting

$$
P(x)=\frac{2}{\sqrt{ } \pi} \int_{0}^{x} \cdot e^{-\zeta^{2}} d \zeta .
$$

$$
\begin{gathered}
\tau=c t / b^{2}, \quad \delta=\gamma^{3} /\left(1+\gamma^{3}\right), \\
\varphi(\gamma, \tau)=\frac{1}{\gamma\left(2 \gamma^{3}+1\right)}\{P(\gamma \sqrt{ } \tau)-\delta \\
\left.+\delta e^{-\left(1-\delta^{2}\right) \gamma^{2} \tau}[1-P(\delta \gamma \sqrt{ } \tau)]\right\},
\end{gathered}
$$

we derive the value of the time settlement function for a suddenly applied sinusoidal load at $t=0$,

$$
w_{s}=b a p_{0} \varphi(\gamma, \tau) \cos \lambda x
$$

\section{SETTLEMENT OF PERFECTLY POROUS SLAB UNDER A CONCENTRATED LOAD}

From the value of the sinusoidal settlement we derive the settlement under an arbitrary load distribution $p_{0}(x)$ by using a Fourier integral representation of the load.

$$
p_{0}(x)=\frac{1}{\pi} \int_{0}^{\infty} d \lambda \int_{-\infty}^{+\infty} p_{0}\left(x_{1}\right) \cos \lambda\left(x-x_{1}\right) d x_{1} .
$$

The corresponding settlement of the slab will be

$$
\begin{array}{r}
w_{s}(x)=\frac{a}{\pi} \int_{0}^{\infty} d \gamma \int_{-\infty}^{+\infty} p_{0}\left(x_{1}\right) \varphi(\gamma, \tau) \\
\times \cos \frac{\gamma}{b}\left(x-x_{1}\right) d x_{1}
\end{array}
$$

or

$$
\begin{aligned}
w_{s}(x)=\frac{a}{\pi} \int_{0}^{\infty} p_{0}\left(x_{1}\right) d x_{1} \int_{0}^{\infty} d \gamma \varphi(\gamma, \tau) \\
\\
\times \cos \frac{\gamma}{b}\left(x-x_{1}\right)
\end{aligned}
$$

Now if we have a concentrated load $P$ extending over an infinitesimal interval $x=-\epsilon$ to $x=\epsilon$ we may write,

$$
P=\int_{-\epsilon}^{+\epsilon} p_{0}\left(x_{1}\right) d x_{1}
$$

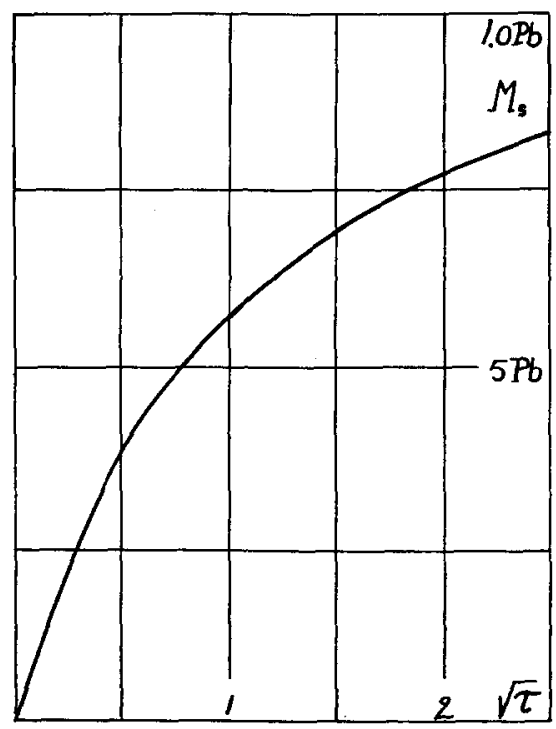

FIG. 2. Maximum bending moment due to settlement as a function of $\sqrt{ } \tau=(c t)^{\frac{1}{1} / b}$. 
and the settlement becomes

$$
w_{s}(x)=\frac{a P}{\pi} \int_{0}^{\infty} \varphi(\gamma, \tau) \cos \gamma \xi d \gamma
$$

with $x / b=\xi$.

In order to integrate this function the following approximations for $\varphi(\gamma, \tau)$ are substituted,

$$
\begin{gathered}
\varphi\left[\gamma,(0.5)^{2}\right]=7.05 \gamma e^{-4.1 \gamma}-0.7 e^{-5 \gamma} \\
-0.062 e^{-1.7 \gamma}+1.32 e^{-8.06 \gamma}, \\
\varphi\left[\gamma,(1.0)^{2}\right]=17.0 \gamma e^{-4.6 \gamma}-1.6 e^{-5 \gamma} \\
-0.062 e^{-1.7 \gamma}+2.79 e^{-9.00 \gamma} \\
\varphi\left[\gamma,(1.5)^{2}\right]=25.0 \gamma e^{-4.9 \gamma}-3.4 e^{-6.7 \gamma} \\
-0.160 e^{-2 \gamma}+5.25 e^{-9.04 \gamma} \\
\varphi\left[\gamma,(2.0)^{2}\right]=32.6 \gamma e^{-5.2 \gamma}-1.1 e^{-5 \gamma}
\end{gathered}
$$

$$
-0.060 e^{-2 \gamma}+3.41 e^{-11.2 \gamma},
$$

$\varphi\left[\gamma,(2.5)^{2}\right]=37.6 \gamma e^{-5.3 \gamma}-1.4 e^{-6.7 \gamma}$

$$
-0.160 e^{-2 \gamma}+4.38 e^{-10.8 \gamma},
$$

$$
\begin{aligned}
\varphi[\gamma, \infty]= & 46.6 \gamma e^{-5.6 \gamma}+13.5 e^{-10 \gamma} \\
& -0.115 e^{-2.5 \gamma}+0.0148 e^{-\gamma} .
\end{aligned}
$$

(2.6) for the concentrated load.

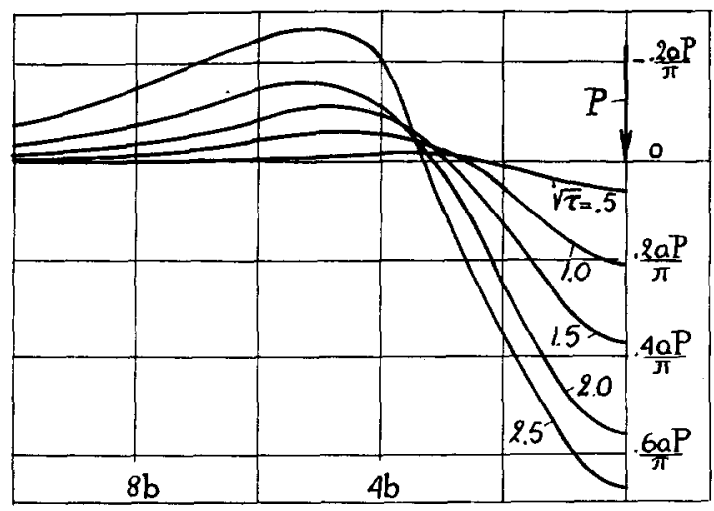

FIG. 3. Settlement of an impervious slab under a concentrated load $P$ at various instants $\left(\sqrt{ } \tau=(c t)^{3} / b\right)$.

Also, if it is desired to secure the value of the bending moment due to settlement, this is given by

$$
M_{s}=-E I \frac{d^{2} w_{s}}{d x^{2}}=b^{2} p_{0} \gamma^{2} \varphi(\gamma, \tau) \cos \lambda x
$$

for the sinusoidal load, or

$$
M_{s}=\frac{P b}{\pi} \int_{0}^{\infty} \gamma^{2} \varphi(\gamma, \tau) \cos \gamma \xi d \gamma
$$

When these are integrated we then have the following:

$$
\begin{aligned}
& w_{s}\left[\tau=(0.5)^{2}\right]=\frac{a P}{\pi}\left[7.05 \frac{16.8-\xi^{2}}{\left[16.8+\xi^{2}\right]^{2}}-\frac{3.50}{25+\xi^{2}}-\frac{0.11}{2.89+\xi^{2}}+\frac{10.6}{64.9+\xi^{2}}\right], \\
& w_{s}\left[\tau=(1.0)^{2}\right]=\frac{a P}{\pi}\left[17.0 \frac{21.1-\xi^{2}}{\left[21.1+\xi^{2}\right]^{2}}-\frac{8.00}{25+\xi^{2}}-\frac{0.11}{2.89+\xi^{2}}+\frac{25.1}{81.0+\xi^{2}}\right] \\
& w_{s}\left[\tau=(1.5)^{2}\right]=\frac{a P}{\pi}\left[25.05 \frac{24.0-\xi^{2}}{\left[24.0+\xi^{2}\right]^{2}}-\frac{22.7}{44.9+\xi^{2}}-\frac{0.32}{4+\xi^{2}}+\frac{47.46}{81.7+\xi^{2}}\right] \\
& w_{s}\left[\tau=(2.0)^{2}\right]=\frac{a P}{\pi}\left[32.6 \frac{27.0-\xi^{2}}{\left[27.0+\xi^{2}\right]^{2}}-\frac{5.5}{25+\xi^{2}}-\frac{0.12}{4+\xi^{2}}+\frac{38.2}{125+\xi^{2}}\right] \\
& w_{s}\left[\tau=(2.5)^{2}\right]= \\
& M_{s}[\tau=\infty]
\end{aligned}
$$


In Fig. 1 are plotted the settlements at various instants, and Fig. 2 shows how the bending due to the settlement at the location of the load varies with time. We note that for $t=\infty$ the limiting value of this bending moment

$$
M_{8}=0.1038 P b \text {. }
$$

In order to check the accuracy of the above method we may derive this expression by using the value of the bending moment obtained previously ${ }^{2}$ in the case of a purely elastic foundation. By an easy adaptation of the formula to the case of two-dimensional strain the bending moment under the load is

$$
M=\frac{2}{3 \sqrt{ } 3}\left[\frac{2\left(1-\nu^{2}\right)}{1+\nu}\right]^{1} P b
$$

where $\nu$ is the Poisson ratio of the elastic foundation and $b$ is defined as above. Now in the case of a consolidating foundation the bending moment immediately after loading corresponds to an incompressible foundation $\left(\nu=\frac{1}{2}\right)$. This value is

$$
M_{0}=\frac{2}{3 \sqrt{ } 3} P b
$$

The bending moment for $t=\infty$ corresponds to $\nu=0$, hence

$$
M_{\infty}=\frac{2}{3 \sqrt{ } 3} 2^{\frac{1}{3}} P b .
$$

The maximum bending moment due to settlement is the difference between these expressions

$$
M_{0}-M_{\infty}=0.100 P b,
$$

which is in fair agreement with the value (2.10) above.

\section{SETTLEMENT OF A SLAB IMPERVIOUS TO WATER UNDER A SINUSOIDALLY DISTRIBUTED LOADING}

Proceeding as before we have instead of (1.3) the relation obtained in a previous paper ${ }^{3}$ for the settlement of a soil in the case in which no water was allowed to escape from the top surface.

$$
w_{0}=\frac{A a}{\lambda}\left[1+\frac{1}{p / c \lambda^{2}+\left(1+p / c \lambda^{2}\right)^{\frac{1}{2}}}\right] \text {. }
$$

Combining this with (1.2) we then have the expression corresponding to (1.4)

$$
w_{0}=\frac{p_{0} a}{\lambda\left[E I \lambda^{3} a+\frac{1}{1+1 /\left(p / c \lambda^{2}+\left[1+p / c \lambda^{2}\right]^{\frac{1}{3}}\right)}\right]} \text {. }
$$

As before we find the deflection at $t=0$ and since we are interested primarily in the settlement due to consolidation of the soil, we will subtract this original deflection and obtain the value of the settlement

$$
w_{s}=\left[w_{0}-\frac{p_{0} a}{\lambda\left(E I \lambda^{3} a+1\right)}\right] \cos \lambda x=\frac{b a p_{0}}{\gamma\left(\gamma^{3}+1\right)} \frac{\left(\gamma^{3}+1\right)\left(p / c \lambda^{2}\right)-\left[\left(1+p / c \lambda^{2}\right)\right]^{\frac{1}{2}}+\gamma^{3}}{\left(\gamma^{3}+1\right)^{2}\left(p / c \lambda^{2}\right)^{2}+\left(\gamma^{6}-1\right)\left(p / c \lambda^{2}\right)-2 \gamma^{3}-1} \cos \lambda x
$$

with the same notation as above: $E I a=b^{3}, \gamma=b \lambda$. 
By factoring the denominator and separating into partial fractions we obtain forms which can be evaluated by (1.7).

Making the same substitutions as before, $\tau=c t / b^{2}$, we obtain the expression corresponding to (1.9) and (1.8)

$$
\begin{aligned}
& w_{s}=b a p_{0} \psi(\gamma, \tau) \cos \lambda x \text {, } \\
& \psi(\gamma, \tau)=\frac{1}{\gamma\left(1+\gamma^{3}\right)^{2}}\left\{\frac{2\left(\left[\left(\gamma^{3}+1\right) /\left(\gamma^{3}+5\right)\right]^{\frac{1}{3}}-1\right)}{1-\frac{1}{4}\left(1-\left[\left(\gamma^{3}+5\right) /\left(\gamma^{3}+1\right)\right]^{\frac{1}{2}}\right)}\left(1-P\left[\frac{1}{2}\left(1-\left[\left(\gamma^{3}+5\right) /\left(\gamma^{3}+1\right)\right]\right)^{\frac{1}{2}} \gamma \sqrt{ } \tau\right]\right)\right. \\
& \times \exp \left[\left(\frac{1}{4}\left[1-\left[\left(\gamma^{3}+5\right) /\left(\gamma^{3}+1\right)\right]^{\frac{1}{3}}\right]^{2}-1\right) \tau \gamma^{2}\right]-\frac{\left(\gamma^{3}+1\right)^{2}}{2 \gamma^{3}+1}\left(\frac{\gamma^{3}}{\gamma^{3}+1}-P[\gamma \sqrt{ } \tau]\right) \\
& -\frac{\frac{1}{2}\left(\left[\left(\gamma^{3}+1\right) /\left(\gamma^{3}+5\right)\right]^{\frac{1}{2}}+1\right)}{1-\frac{1}{4}\left(1+\left[\left(\gamma^{3}+5\right) /\left(\gamma^{3}+1\right)\right]^{\frac{1}{2}}\right)^{2}}\left(1-P\left[\frac{1}{2}\left(1+\left[\left(\gamma^{3}+5\right) /\left(\gamma^{3}+1\right)\right]^{\frac{1}{2}}\right) \gamma \sqrt{ } \tau\right]\right) \\
& \times \exp \left[\left(\frac{1}{4}\left[1+\left[\left(\left(\gamma^{3}+5\right) /\left(\gamma^{3}+1\right)\right]^{\frac{1}{2}}\right]^{2}-1\right) \tau \gamma^{2}\right]\right\} .
\end{aligned}
$$

\section{SETTLEMENT OF IMPERVIOUS SLAB UNDER A CONCENTRATED LOAD}

The settlement due to a concentrated load $P$ is

$$
w_{s}(x)=\frac{a P}{\pi} \int_{0}^{\infty} \psi(\gamma, \tau) \cos \gamma \xi d \gamma
$$

The following approximations for $\psi(\gamma, \tau)$ are

$$
\begin{aligned}
& \psi\left[\gamma,(0.5)^{2}\right]=\frac{1}{4} \gamma e^{-3.3 \gamma}+0.25 \gamma^{2} e^{-2 \gamma^{2}}, \\
& \psi\left[\gamma,(1.0)^{2}\right]=\gamma e^{-3.6 \gamma}+1.48 \gamma^{2} e^{-3.1 \gamma^{2}}+0.065 \gamma^{4} e^{-1.5 \gamma^{2}}, \\
& \psi\left[\gamma,(1.5)^{2}\right]=2.25 \gamma e^{-3.9 \gamma}+3.2 \gamma^{2} e^{-3.5 \gamma^{2}}+0.04 \gamma^{4} e^{-1.5 \gamma^{2}}, \\
& \psi\left[\gamma,(2.0)^{2}\right]=4 \gamma e^{-4.4 \gamma}+2.5 \gamma^{2} e^{-3.1 \gamma^{2}}+4.4 \gamma^{2} e^{-5.5 \gamma^{2}}, \\
& \psi\left[\gamma,(2.5)^{2}\right]=6.25 \gamma e^{-4.7 \gamma}+1.52 \gamma^{2} e^{-3.8 \gamma}+8.3 \gamma^{2} e^{-4.7 \gamma^{2}}-4.0 \gamma^{4} e^{-6.1 \gamma^{2}}
\end{aligned}
$$

The bending moment and settlement at $\tau=\infty$ are the same as before. When (4.1) is integrated with the approximation given in (4.2) we obtain

$$
\begin{aligned}
& w_{s}\left[\tau=(0.5)^{2}\right]=\frac{a P}{\pi}\left[\frac{1}{4} \frac{11.9-\xi^{2}}{\left(11.9+\xi^{2}\right)^{2}}+0.0391\left(1-\xi^{2} / 4\right) \exp \left(-\xi^{2} / 8\right)\right], \\
& \begin{aligned}
w_{s}\left[\tau=(1.0)^{2}\right]=\frac{a P}{\pi}\left[\frac{13.0-\xi^{2}}{\left(13.0+\xi^{2}\right)^{2}}+0.120\left(1-\xi^{2} / 6.2\right) \exp \left(-\xi^{2} / 12.4\right)\right. & \left.+0.00524\left(3-2 \xi^{2}+\xi^{4} / 9\right) \exp \left(-\xi^{2} / 6\right)\right], \\
w_{s}\left[\tau=(1.5)^{2}\right]=\frac{a P}{\pi}\left[\frac{9}{4} \frac{15.2-\xi^{2}}{\left(15.2+\xi^{2}\right)^{2}}+0.216\left(1-\xi^{2} / 7\right) \exp \left(-\xi^{2} / 14\right)\right. & \left.+0.00322\left(3-2 \xi^{2}+\xi^{4} / 9\right) \exp \left(-\xi^{2} / 6\right)\right],
\end{aligned}
\end{aligned}
$$




$$
\begin{aligned}
& w_{s}\left[\tau=(2.0)^{2}\right]=\frac{a P}{\pi}\left[4 \frac{19.4-\xi^{2}}{\left(19.4+\xi^{2}\right)^{2}}+0.151\left(1-\xi^{2} / 6.2\right) \exp \left(-\xi^{2} / 12.4\right)\right. \\
& \left.\quad+0.151\left(1-\xi^{2} / 11\right) \exp \left(-\xi^{2} / 22\right)\right] \\
& \begin{array}{c}
w_{8}\left[\tau=(2.5)^{2}\right]=\frac{a P}{\pi}\left[\frac{25}{4} \frac{22.1-\xi^{2}}{\left(22.1+\xi^{2}\right)^{2}}+11.64 \frac{14.4-3 \xi^{2}}{\left(14.4+\xi^{2}\right)^{3}}+0.361\left(1-\xi^{2} / 9.4\right) \exp \left(-\xi^{2} / 18.8\right)\right. \\
\left.-0.00963\left(3-0.492 \xi^{2}+\xi^{4} / 149\right) \exp \left(-\xi^{2} / 24.4\right)\right] .
\end{array}
\end{aligned}
$$

Figure 3 shows the above value of $w_{s}$ plotted. In comparison with Fig. 1 it is seen that the prevention of water flow from the top surface decreases the rate of settlement. However, the amount of the bending moment at $\tau=0$ and $\tau=\infty$ is the same for both cases. Also, it can be seen that at a position $\xi=3.5$ very little settlement takes place in the case of the impervious slab.

\title{
Emissivities and Temperature Scales of the Iron Group
}

\author{
H. B. Wahlin and Rufus Wright \\ Department of Physics, University of Wisconsin, Madison, Wisconsin
}

(Received September 18, 1941)

\begin{abstract}
The temperature scales have been determined for well-degassed specimens of the iron group and from these the emissivity for $\lambda=0.667 \mu$ is calculated. Over the range of temperatures covered the emissivity is nearly a constant except at the $A_{3}$ point in iron where there is a sudden change.
\end{abstract}

$I^{\mathrm{N}}$ $\mathrm{N}$ a study of the thermionic properties of the iron group, the results of which will be published elsewhere, it was thought advisable to determine the temperature scales of the elements under the same condition of vacuum heat treatment as is used in thermionic studies. The results reported by Whitney ${ }^{1}$ and Wahlin and Whitney ${ }^{2}$ have shown that important changes in the spectral emissivity and therefore in the temperature scales may be obtained by prolonged heating in a vacuum. The work on iron, nickel, and cobalt has yielded values differing sufficiently from those already in the literature so as to justify their publication in a separate paper.

\section{THE OPTICAL PYROMETER}

The disappearing filament optical pyrometers used in the measurements were modifications of

${ }^{1}$ L. V. Whitney, Phys. Rev. 48, 458 (1935).

${ }^{2}$ H. B. Wahlin and L. V. Whitney, J. Chem. Phys. 6, 594 (1938). the design proposed by Fairchild and Hoover. ${ }^{3}$ Instead of a pyrometer lamp with a 3-mil filament, as is quite commonly used, a special lamp with a 1.5-mil filament was substituted. The result of this is that a greater latitude in the apertures of the optical system is permissible and a better match can be obtained, especially at the lower temperatures. Observers who had been using instruments with the larger filaments insisted that they could not get as good a match with the smaller filament but with a little practice did as well. The authors wish it understood that they are not presenting a brief for the use of the smaller filaments but are simply stating their own experience.

Three pyrometers with objectives of different focal lengths were calibrated by sectoring up and down from the gold point, using carefully calibrated sectors. They were then compared by

${ }^{3}$ C. O. Fairchild and W. H. Hoover, J. Opt. Soc. Am. 7, 543 (1923). 